\title{
Prediction of Tractor Sideslipping Behavior Using a Quasi-static Model
}

\section{Li, Zhen}

Laboratory of Bioproduction Engineering, Division of Bioproduction Environmental Sciences, Department of Agro-environmental Sciences, Graduate School of Bioresource and Bioenvironmental Sciences, Kyushu University

\section{Mitsuoka, Muneshi}

Laboratory of Bioproduction Engineering, Division of Bioproduction Environmental Sciences, Department of Agro-environmental Sciences, Faculty of Agriculture, Kyushu University : Assistant Professor

\section{Inoue, $\mathrm{Eiji}$}

Laboratory of Bioproduction Engineering, Division of Bioproduction Environmental Sciences, Department of Agro-environmental Sciences, Faculty of Agriculture, Kyushu University : Professor

\section{Okayasu, Takashi}

Laboratory of Bioproduction Engineering, Division of Bioproduction Environmental Sciences, Department of Agro-environmental Sciences, Faculty of Agriculture, Kyushu University : Associate Professor

他

https://doi.org/10.5109/1526314

出版情報：九州大学大学院農学研究院紀要. 60 (1)，pp.215-218，2015-02-27. Faculty of Agriculture, Kyushu University バージョン :

権利関係 : 


\title{
Prediction of Tractor Sideslipping Behavior Using a Quasi-static Model

\author{
Zhen LI ${ }^{1}$, Muneshi MITSUOKA ${ }^{2 *}$, Eiji INOUE ${ }^{2}$, Takashi OKAYASU ${ }^{2}$, \\ Yasumaru HIRAI ${ }^{2}$ and Zhongxiang $\mathrm{ZHU}^{3}$
}

\author{
Laboratory of Bioproduction Engineering, Division of Bioproduction Environmental Sciences, \\ Department of Agro-environmental Sciences, Faculty of Agriculture, \\ Kyushu University, Fukuoka 812-8581, Japan
} \\ (Received October 31, 2014 and accepted November 14, 2014)
}

\begin{abstract}
Tractor stability predominantly determines operator's safety. For a tractor parking on lateral slopes, overturning accidents have been frequently discussed using mathematical models. While the existing static models remarkably contribute tractor overturning mechanisms, few of them have considered the stability from the perspective of tractor sideslip. In our study, a relatively precise quasi-static model presented recently was adopted as the base model. We expanded it by introducing potential tractor sideslips. While the original model pointed out the lateral slope angle as the main factor influencing tractor overturns, we investigated tractor slipping stability under the influences of the slope angle and the coefficient of friction. The dimensional parameters of the example tractor for simulation were set the same as those in the original work. It was found that the allowable friction forces of both the front and rear tires primarily depended on the coefficient of friction rather than the slope angle. By comparing the surfaces of the allowable friction forces and the corresponding friction forces, tractor slipping thresholds for the front and rear tires were identified. Caution areas implying certain ground conditions that will definitely cause tractor sideslip were marked accordingly. The results shown in this study provide a relatively comprehensive way to understand tractor static stability when both tractor sideslip and overturn are concerned.
\end{abstract}

Key words: Tractor Sideslip, Quasi-static Model, Lateral Slope

\section{INTRODUCTION}

There is no doubt that tractor stability greatly influences the operation efficiency of tractor and the safety of operator. It is therefore necessary to understand how tractor stability varies under the influences of certain factors. Despite the contributions of trial observations (Chisholm, 1979) and virtual prototyping approaches (Du et al., 2011; Li et al., 2014; Zhu et al., 2014), mathematical modeling provides a way to look into the fundamental mechanism. In this way, it is possible to analyze and further predict tractor status for various conditions (Ahmadi, 2011, 2013; Li et al., 2014a, 2014b; Schwanghart, 1973).

For a parked tractor, quasi-static (or static) conditions are often considered to theoretically identify the critical ground parameters. However, most of the existing models mainly deal with tractor overturning behaviors (Guzzomi, 2012; Matsuyama et al., 1970; Nichol et al., 2005; Smith et al., 1974). While a tractor immediately loses control when it slips to the side, it is unclear that how the tractor reacts in terms of sideslip with more

\footnotetext{
1 Laboratory of Bioproduction Engineering, Division of Bioproduction Environmental Sciences, Department of Agroenvironmental Sciences, Graduate School of Bioresource and Bioenviron-mental Sciences, Kyushu University, Japan

2 Laboratory of Bioproduction Engineering, Division of Bioproduction Environmental Sciences, Department of Agroenvironmental Sciences, Faculty of Agriculture, Kyushu University, Japan

3 College of Engineering, China Agricultural University, China

* Corresponding author (E-mail: mitsuoka@bpes.kyushu-u. ac.jp)
}

than one external factor varying. Thus, the stability of tractor indicating the resistances to overturns and sideslips gives a more comprehensive interpretation. For quasi-static modeling, the approach proposed by Guzzomi (2012) revised some key limitations of previous relevant models. It suitably considered tractor physical configurations and precisely analyzed the variations of the ground supporting forces which determine the initiations of Phase I tractor overturn. We therefore adopted this model as the base model in this study.

Our objectives are to introduce tractor potential sideslip into Guzzomi's (2012) model, and to investigate the influences of certain factors on tractor slipping behavior. According to the results, tractor slipping thresholds for the front and rear tires were given. Furthermore, the risky ground conditions on which a given tractor must avoid traveling were identified.

\section{MATERIALS AND METHODS}

\section{Adopted quasi-static model}

A tractor quasi-static model for the prediction of lateral overturn assumes that the lateral slope on which the tractor stays increases quasi-statically. Therefore any status of the tractor during this process can be regarded to be in static balance, until the threshold is reached. In some existing models, a line through the front axle pivot and the ground-contacting point of the downhill rear tire is commonly accepted as the roll axis (Scarlett et al., 2006). On the contrary, Guzzomi (2012) stated the impropriety of such definition considering the physical rotation con-straint. Upon this point, Guzzomi (2012) proposed a revised mathematical model taking into con- 
sideration the practical configuration of tractor front end, for predicting the initiation of Phase I overturn. By dividing the tractor into the anterior part (tractor front end) and the poste-rior part (main body), the mathematical model was formulated using free body analysis. Be-cause the variations of the normal forces applied to the tires directly determine tractor's stability, Guzzomi (2012) precisely presented these forces as follows:

$$
\begin{aligned}
F_{\mathrm{R} 1} & =\frac{m g}{w}\left[-\frac{l_{r}}{L}\left(h_{1} \sin \theta+\frac{w}{2} \cos \theta\right)+\left(h_{1}+e_{y}\right) \sin \theta\right. \\
& \left.+\left(\frac{w}{2}+e_{x}\right) \cos \theta\right] \\
F_{\mathrm{R} 2} & =\frac{m g}{w}\left[\frac{l_{r}}{L}\left(h_{1} \sin \theta-\frac{w}{2} \cos \theta\right)-\left(h_{1}+e_{y}\right) \sin \theta\right. \\
& \left.+\left(\frac{w}{2}-e_{x}\right) \cos \theta\right] \\
F_{\mathrm{F} 3} & \frac{m g}{w}\left(\frac{l_{r}}{L}\right)\left(\frac{w}{2} \cos \theta-h_{1} \sin \theta\right) \\
F_{\mathrm{F} 4} & =\frac{m g}{w}\left(\frac{l_{r}}{L}\right)\left(\frac{w}{2} \cos \theta+h_{1} \sin \theta\right)
\end{aligned}
$$

where $F_{\mathrm{R} 1 / 2}$ is the normal force applied to the downhill/ uphill rear tire, $\mathrm{N} ; F_{\mathrm{F} 3 / 4}$ is the normal force applied to the uphill/downhill front tire, $\mathrm{N} ; m$ is the tractor mass, $\mathrm{kg}$; $\mathrm{g}$ is the acceleration of gravity, $m \mathrm{~s}^{-2}$; $\mathrm{w}$ is the track width, $\mathrm{m} ; l_{r}$ is the horizontal distance between the COG and the rear axle, $\mathrm{m} ; L$ is the wheel base, $\mathrm{m} ; h_{1}$ is the height of the front axle pivot, $\mathrm{m} ; \theta$ is the lateral slope angle, rad; $e_{x}$ is the horizontal distance between the COG and the tractor midplane, $\mathrm{m} ; e_{y}$ is the COG height above $h_{1}, \mathrm{~m}$.

Considering two conditions initializing Phase I tractor overturn, the overturning initial angles of the uphill front and rear tires were further obtained by given Equation (3) = 0 while Equation $(2) \neq 0$, and Equation (2) $=0$ while Equation $(3) \neq 0$, respectively.

This model precisely derives the expressions of the normal forces and subsequently provides a threshold in terms of static overturn. Considering the completeness and the expandability of Guzzomi's work (2012), it is adopted as the base model in this study.

\section{Introduction of tractor sideslip}

In Guzzomi's study (2012), the coefficient of friction between the ground and the tires was assumed to be nonlimiting, for providing the tractor a non-sideslip condition. In fact, however, there always exists a certain value of the coefficient of friction. Once the maximum friction for-ce is reached, the tractor will face a slipping problem which is also identified as risky to operators.

To investigate tractor sideslips, the influence of the lateral slope angle and the coefficient of friction should be both taken into consideration. Therefore the expressions used in Guzzomi's model (2012): $\mu F_{\mathrm{F}}$ and $\mu F_{\mathrm{R}}$ are replaced by $f_{\mathrm{F}}$ and $f_{\mathrm{R}}$ in this study, where $\mu$ is the coeffi- cient of friction between the ground and the tires, $F_{\mathrm{F} / \mathrm{R}}$ is the total normal force applied to the front/rear tires, N; $f_{\mathrm{FR}}$ is the total friction force applied to the front/rear tires, N. $f_{\mathrm{F} / \mathrm{R}}$ can be obtained through the following equations:

$$
\begin{gathered}
f_{\mathrm{F}}+f_{\mathrm{R}}-m g \sin \theta=0 \\
\left(L-l_{r}\right) f_{\mathrm{F}}-l_{r} f_{\mathrm{R}}=0
\end{gathered}
$$

Substituting $f_{\mathrm{F}}=\left(l_{r} / L\right) m g \sin \theta$ and $f_{\mathrm{R}}=\left[\left(L-l_{r}\right) / L\right]$ $m$ gsin $\theta$ into Guzzomi's (2012) modeling process recovers equations (1)-(4). The initiation of tractor sideslip is then defined when $f_{\mathrm{F} / \mathrm{R}}=f_{\text {limit-F/R }}$, where $f_{\text {limit-F/R }}$ is the maximum static friction force of the front/rear tires $(\mathrm{N})$, and is de-fined as:

$$
f_{\text {limit-F/R }}=\mu F_{\mathrm{F} / \mathrm{R}}
$$

Therefore, $f_{\text {limit-F/R }}$ is a dependent variable as functions of the independent variables: $\theta$ and $\mu$. In this way, the lateral slope angle and the road roughness together determine tractor slipping behaviors while only the latter affects tractor overturns. Hence, it is possible to predict if the tractor will firstly slip or overturn for a given $\mu$ and $\theta$.

\section{RESULTS AND DISCUSSION}

For comparison, the key dimensional parameter values for the example tractor were cited from Guzzomi's work (2012), as listed in Table 1. Note that the COG

Table 1. Dimensional parameters of the example tractor given by Guzzomi (2012)

\begin{tabular}{ccc}
\hline Parameter & Value & Units \\
\hline$m$ & 3000 & $\mathrm{~kg}$ \\
$L$ & 2.25 & $\mathrm{~m}$ \\
$w$ & 1.05 & $\mathrm{~m}$ \\
$l_{r}$ & 0.90 & $\mathrm{~m}$ \\
$h_{1}$ & 0.55 & $\mathrm{~m}$ \\
$e_{x}$ & 0 & $\mathrm{~m}$ \\
$e_{y}$ & 0.35 & $\mathrm{~m}$ \\
\hline
\end{tabular}

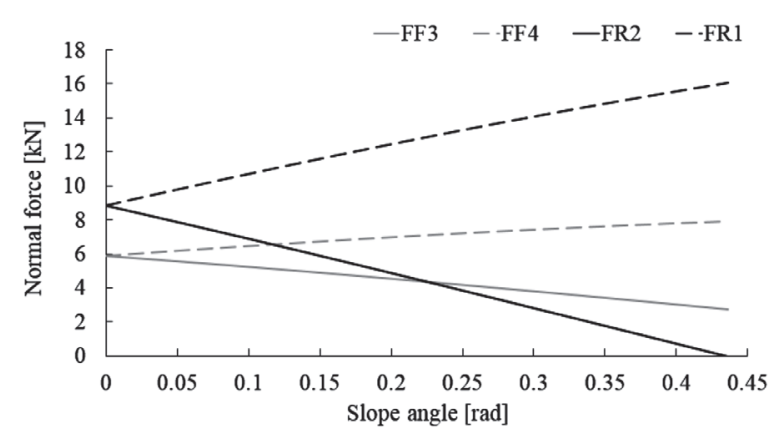

Fig. 1. Reproduced result of the variations of the normal forces applied to the tires considering the example tractor, previously predicted by Guzzomi (2012). 
was assumed to be located in the tractor midplane for simplifying the simulation, indicating that $e_{x}=0$. Substituting these pa-rameters into equations (1)-(7) precisely recovers the variations of the normal forces applied to the tires predicted by Guzzomi (2012), shown in Fig. 1. It further proves the rationality of introducing equations (5) and (6). It can be clearly seen that for the tractor with parameters given in Table 1, the uphill rear tire will firstly lose contact with the ground when the lat-

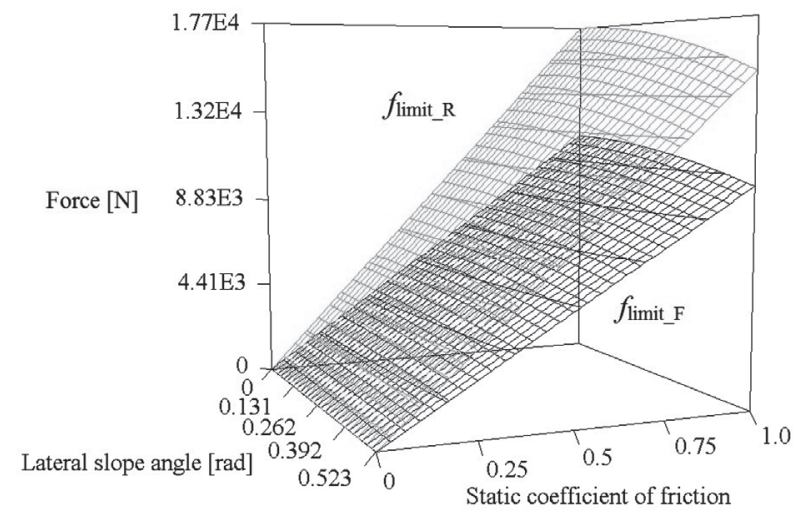

Fig. 2. Variations of the allowable friction forces of the front and rear tires.

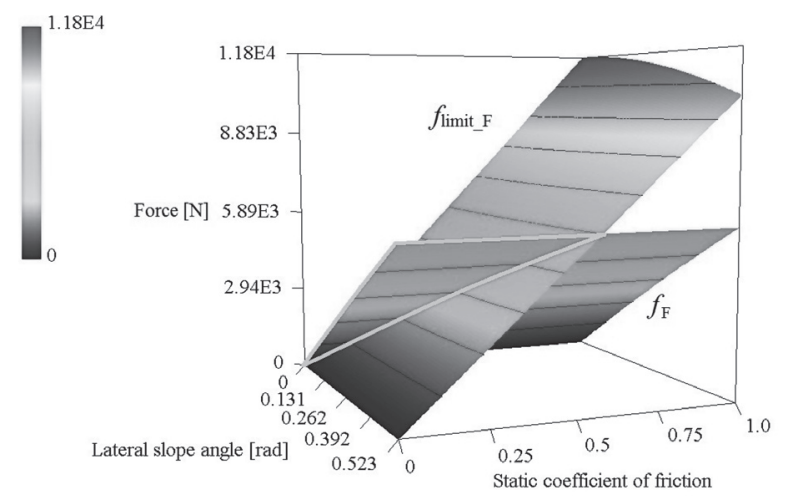

Fig. 3. Total friction force applied to the front tires and its limit value as functions of the lateral slope angle and the static coefficient of friction.

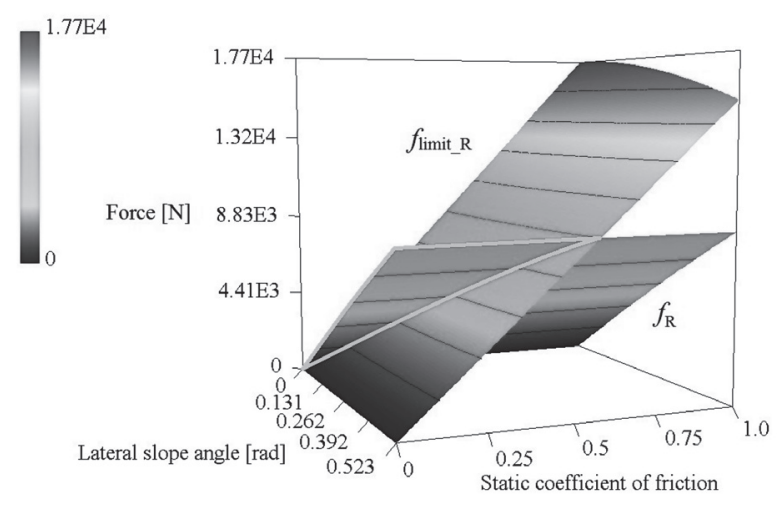

Fig. 4. Total friction force applied to the rear tires and its limit value as functions of the lateral slope angle and the static coefficient of friction. eral slope angle approximately reaches $0.436 \mathrm{rad}\left(25^{\circ}\right)$. Therefore it is a type of "loss of up-slope rear (PI-R) tire contact (denoted by Guzzomi, 2012)" Phase I overturn.

From the aspect of sideslip, however, the lateral slope angle is not the only factor influencing tractor stability. Noting that the tractor's heading direction is parallel to the sloping surface, tractor sideslip then can be categorized into front-slip and rear-slip types. The total lateral friction forces generated at the front and rear tires are compared with their corresponding limit values. Once $f_{\mathrm{FR}}=f_{\text {limit_FR }}$, the sideslip threshold is reached and a danger arises. It should be noted that if there is a chance that sideslip happens before tractor overturn, the main concern should never be on tractor overturning precaution only.

To investigate the effects of the lateral slope angle $(\theta)$ and the static coefficient of friction $(\mu)$ on tractor slipping stability, we set their ranges to be $0-0.523 \mathrm{rad}$ $\left(0-30^{\circ}\right)$ and $0-1$, respectively. Fig. 2 shows the limit values that $f_{\mathrm{F}}$ and $f_{\mathrm{R}}$ can reach. The result shows that the maximum static friction force of the rear tires is greater than that of the front tires overall. As the static coefficient of friction increases, the allowable friction forces of both the front and rear tires increase dramatically. Specifically, $f_{\text {limt }-\mathrm{R}}$ apparently climbs faster than $f_{\text {limt }-\mathrm{F}}$. Furthermore, it can be concluded that the lateral slope angle has much less influence on $f_{\text {limt }-\mathrm{F} / \mathrm{R}}$ than the static coefficient of friction.

Fig. 3 shows the predicted friction force applied to the front tires comparing with its limit value. Different from the variation of $f_{\text {limit-F}}, f_{\mathrm{F}}$ mainly depends on the lateral slope angle rather than the static coefficient of friction. The intersection curve of the two surfaces implies the sideslipping threshold $\left(f_{\mathrm{F}}=f_{\text {limit-F }}\right)$. Therefore, the marked area (including the intersection curve) of $f_{\mathrm{F}}$ indicates the ground conditions including certain combinations of $\theta$ and $\mu$ that must be avoided to prevent from sideslip. The variation of the friction force applied to the rear tires is shown in Fig. 4. $f_{\mathrm{R}}$ shows the similar tendency as $f_{\mathrm{F}}$. Furthermore, comparing the force values in Figs. 3 and 4 , one can find that the front tires are more likely to skid downhill than the rear tires considering the example tractor.

\section{CONCLUSION}

Considering a tractor quasi-static model, we rebuilt and expanded the original mathematical model developed by Guzzomi (2012). In our study, tractor skidding behavior was introduced and discussed as another factor influencing tractor stability. The introduction of the equations describing the lateral friction forces did not change the fundamental methodology used in the work of Guzzomi (2012), which was proved by the reproduced result shown in Fig. 1.

We further investigated the effects of the lateral slope angle and the static coefficient of friction on tractor slipping behavior. The allowable values of $f_{\mathrm{F}}$ and $f_{\mathrm{R}}$ were found predominantly depending on the static coef- 
ficient of friction. On the contrary, we found that $f_{\mathrm{F}}$ and $f_{\mathrm{R}}$ mainly depended on the lateral slope angle. According to the tendencies of $f_{\mathrm{FR}}$ and $f_{\text {limit_F }}$, the slipping thresholds for the front and rear tires were identified. The areas referencing these intersection curves indicate certain combinations of $\theta$ and $\mu$ that must be avoided. For the road conditions that stay within the "safe zone", no sideslip will happen to the corresponding tires. However, it should be noted that tractor stability includes the resistances to both sideslips and overturns. Therefore, any road conditions are supposed to be discussed considering tractor sideslipping and overturning stabilities.

\section{ACKNOWLEDGEMENTS}

The authors acknowledge the financial support received from the China Scholarship Council.

\section{REFERENCES}

Ahmadi, I. 2011 Dynamics of tractor lateral overturn on slopes under the influence of position disturbances (model development). J. Terramechanics, 48(5): 339-346

Ahmadi, I. 2013 Development of a tractor dynamic stability index calculator utilizing some tractor specifications. Turk. J. Agric. For., 74(1): 203-211

Chisholm, C. J. 1979 Analysis of rigid-body motion from cine film measurements. J. agric. Engng Res., 24: 441-446

Du, Y. F., Zhu, Z. X., Mao, E. R., Song, Z. H., Gao, J. M. and Zhu, K. G. 2011 Simulation on small-scale corn harvester for hilly area based on ADAMS. Transactions of the Chinese Society for Agricultural Machinery, 42(SUPPL.): 1-5

Guzzomi, A. L. 2012 A revised kineto-static model for Phase I tractor rollover. Biosystems Eng., 113(1): 65-75

Li, F. Q., Liu, S. R., Mao, E. R., Xie, B. and Zhang, L. X. 2014 Structural analysis and optimization of combine harvester frame. Applied Mechanics and Materials, 490-491: 629-632

Li, Z., Mitsuoka, M., Inoue, E., Okayasu, T. and Hirai, Y. $2014 \mathrm{a}$ Dynamic analysis of agricultural wheel tractor driving on uneven surface under the influences of speed and slope angle. $J$. Fac. Agr, Kyushu Univ., 59(2): 339-343

Li, Z., Mitsuoka, M., Inoue, E., Okayasu, T. and Hirai, Y. 2014 b Lateral slope effect on tipping behavior of a tractor encountering an obstacle (model development). J. Fac. Agr., Kyushu Univ., $\mathbf{5 9}(2)$ : 345-349

Matsuyama, T., Kawasaki, K., Fujioka, S., and Maeoka, K. 1970 On the side-overturning angle of the 4 wheel tractor on slope land (I) On the static side-overturning angle. Journal of the Japanese Society of Agricultural Machinery, 32(2): 111-116

Nichol, C. I., Sommer III, H. J., and Murphy, D. J. 2005 Simplified Overturn Stability Monitoring of Agricultural Tractors. Journal of Agricultural Safety and Health, 11(1): 99-108

Scarlett, A. J., Reed, J. N., Semple, D. A., Seward, P. C., Stockton, A. D. and Price, J. S. 2006 Operator roll-over protection on small vehicles. Research report 432. UK: HSE Books.

Schwanghart, H. 1973 Berechnungsmethode fur das unsturzverhalten eines achrschleppers am hang (Method for calculating the overturning behaviour of tractors on slopes). Grundlagen Der Landtechnik, 23(6): 170-176

Smith, D. W., Perumpral, J. V. and Liljedahl, J. B. 1974 The kinematics of tractor sideways over-turning. Trans. ASAE, 17(1): $1-3$

Zhu, Z. X., Li, Z., Xie, B. and Mao, E. R. 2014 Virtual prototyping analysis on gear assembly of the power train for a large-scale combine harvester. Applied Mechanics and Materials, 441: $635-640$ 